\title{
Correction to: Novel Spaced Repetition Flashcard System for the In-training Examination for Obstetrics and Gynecology
}

\author{
Shelun Tsai ${ }^{1} \cdot$ Michael Sun ${ }^{4} \cdot$ Melinda L. Asbury ${ }^{2,4} \cdot$ Jeremy M. Weber ${ }^{3} \cdot$ Tracy Truong $^{3} \cdot$ Elizabeth Deans $^{1}$
}

Published online: 22 June 2021

(C) International Association of Medical Science Educators 2021

Correction to: Medical Science Educator https://doi.org/10.1007/s40670-021-01320-z

The original article has been updated to correct the affiliations for 3 of the authors (Shelun Tsai, Michael Sun, and Melinda Asbury).
Publisher's Note Springer Nature remains neutral with regard to jurisdictional claims in published maps and institutional affiliations.

The original article can be found online at https://doi.org/10.1007/ s40670-021-01320-z.

Shelun Tsai

stsai6326@gmail.com

1 Department of Obstetrics and Gynecology, Duke University Medical Center, Durham, NC, USA

2 Department of Psychiatry, University of North Carolina School of Medicine, Chapel Hill, NC, USA

3 Department of Biostatistics and Bioinformatics, Duke University Medical Center, Durham, NC, USA

4 Department of Psychiatry, Duke University Medical Center, Durham, NC, USA 